\title{
Rebuilding Atlantic Cod: Lessons from a Spawning Ground in Coastal Newfoundland
}

\author{
G.A. Rose, I.R. Bradbury', B. deYoung', S.B. Fudge, G.L. \\ Lawson $^{3}$, L.G.S. Mello, D. Robichaud ${ }^{4}$, G. Sherwood ${ }^{5}$, P.V.R. \\ Snelgrove ${ }^{6}$, and M.J.S. Windle \\ Memorial University, Fisheries and Marine Institute, Fisheries \\ Conservation Group, St. John's, Newfoundland and Labrador, Canada
}

\section{Abstract}

Atlantic cod (Gadus morhua) was studied at the Bar Haven, Placentia Bay, Newfoundland (NAFO 3Ps stock unit) spawning ground from 1996 to 2003. Lessons applicable to management of rebuilding stocks derived from these studies are reviewed: (1) cod spawn in the same area each year, but numbers and timing vary (spawning biomass varied from 2,000 to $25,000 \mathrm{t}$, with timing protracted over at least 100 days); (2) courtship and spawning behavior is complex, and includes lekking, sound production, and vertical rituals; (3) large fish in good condition are necessary to large egg potential because fecundity increases exponentially with fish size-total egg potential varied considerably from year to year with spawning abundance, age changes, and mean liver condition in spawning females; (4) retention of early life stages did not explain local recruitment and rankings of annual densities of eggs, larvae and juveniles did not match with local recruitment during three years of study; (5) dispersal of early life stages, juveniles, and adults was density-dependent; (6) individual adults homed to the same spawn-

Authorship assigned alphabetically after senior author. Present affiliations: 1. Dalhousie University Department of Biology, Halifax, NS, Canada. 2. Department of Physics and Physical Oceanography, Memorial University, St. John's, NL, Canada. 3. Woods Hole Oceanographic Institution, Woods Hole, Massachusetts, USA. 4. LGL Ltd., Sidney, BC, Canada. 5. Gulf of Maine Research Institute, Portland, Maine, USA. 6. Ocean Sciences Centre, Memorial University, St. John's, NL, Canada. 
ing ground in sequential years, but others strayed; (7) egg potential was correlated with the return of adults to the spawning ground 4-5 years later $\left(r^{2}=0.33\right.$, d.f. 3$)$, and with recruitment to the full stock area (NAFO subdivision 3Ps) $\left(r^{2}=0.96\right.$, d.f. 5), with only weak compensation in survival at low stock size; (8) fishing on spawning aggregations may harm reproductive potential; and (9) seasonal fisheries influence fishing mortality, commercial yield, and value. Management implications are discussed.

\section{Introduction}

Fish population dynamics at low stock sizes may differ fundamentally from those at higher stock levels and are not well understood (deYoung and Rose 1993). As a consequence, assumptions and models based on extrapolations from higher population states have proven to be unrealistic in predicting rebuilding rates, such as those for Newfoundland and Labrador cod (e.g., Roughgarden and Smith 1996, Myers et al. 1999, Hutchings 1999). Recent evaluations of stock-recruitment relationships have emphasized the need to better understand the "low end" of the stock-recruitment relationship in stocks that have entered this domain (Walters and Martell 2004), in particular because of the possibility of depensation, which describes a population state in which growth rates do not increase and may even decline at low stock sizes (Liermann and Hilborn 2001). Although Myers et al. (1995) concluded that there was little evidence for depensation across a broad sweep of fish stocks, there is considerable evidence that at least some of the cod stocks in Newfoundland and Labrador waters entered just such a state in the 1990s (Frank and Brickman 2000, Anderson and Rose 2001, Rose 2004, Shelton et al. 2006 ). Nevertheless, it is not at all clear at what life stage depensatory mortality occurs, or if all stocks in this region are in this state.

The place to start in attempting to understand the dynamics of rebuilding in fish stocks is on the spawning grounds. Very few studies have focused on multiyear studies of spawning grounds in marine fishes, with attempts to track the dynamics of a population from spawning fish through the egg and juvenile stages and back to spawning recruits. No study of which we are aware has attempted to do this with a stock at a depressed population level. In the present work, we review the results of a study based at a key spawning ground for Atlantic cod (Gadus morhua) on the south coast of Newfoundland (NAFO subdivision 3Ps management unit), located on the Bar Haven shoals in Placentia Bay (Fig. 1). At the beginning of this work in the mid-1990s, the stock was recovering from a depressed state. Over the past decade it has rebuilt somewhat, although not to historic levels, and now supports the largest fishery in the northwest Atlantic (Brattey et al. 2004). It was during this 


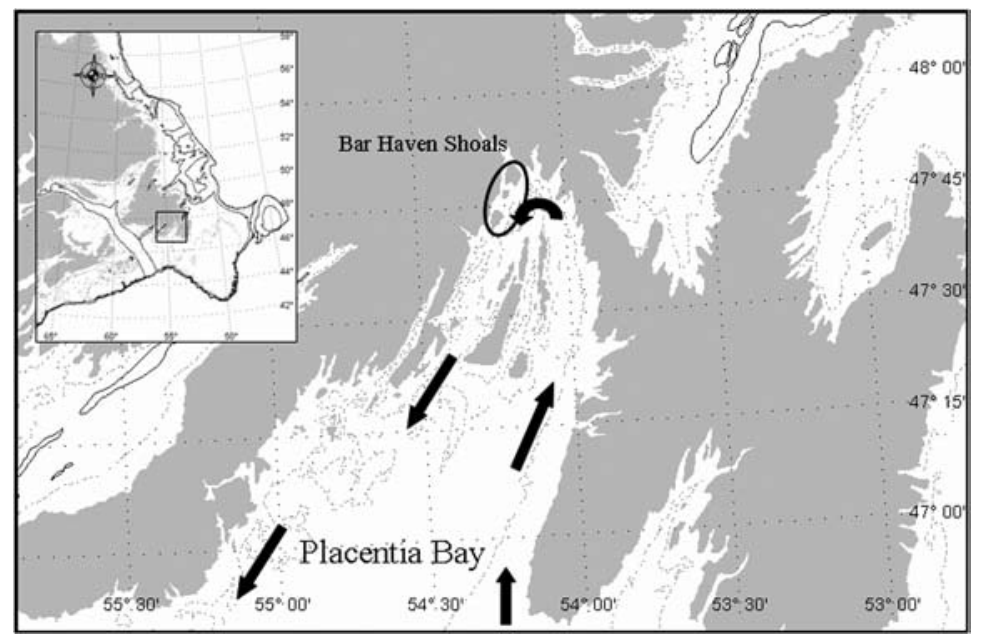

Figure 1. Map of Placentia Bay showing the Bar Haven spawning shoals and dominant currents.

period of moderate growth from a low stock size that we attempted to capture the dynamics of the life history of these fish from spawning to returning next generation adults.

The first objective of this work was to learn about the dynamics of cod populations, especially at low population sizes. Several "lessons," used in the sense of "something learned by study or experience," (Allen 2000) may be gleaned from this work. These form the basis of this review, which represents a synthesis of published research as well as new and more comprehensive interpretations of the data that have been collected. We add new syntheses from egg production and population models that enable comparisons of egg, larval, and juvenile concentrations with recruitment to the local spawning group and to the full management unit stock. We also examine the persistence of the Bar Haven spawning ground. A chronological approach is taken, from spawning adults, their distribution, density, and behavior, through the early life stages, and ending at next-generation recruitment back to the spawning ground and to the full stock.

It was also an objective to use this work to provide information that could advise management. Such advice often assumes compensatory population dynamics (Cook 1998, Frank and Brickman 2000) such that as abundance declines, individual and population growth rates are assumed to increase. These controversial assumptions point to the importance of this study in providing a better understanding of population processes at low stock sizes. 


\section{Methods}

\section{Acoustic surveys and stations}

The timing and distribution of spawning at the Bar Haven ground in Placentia Bay was monitored over eight years (1996-2003) using acoustic survey methods employing calibrated Simrad EK500 split-beam or BioSonics single beam DT4000 echosounders (38 and $120 \mathrm{kHz}, 6-7^{\circ}$ halfpower beam widths) (Lawson and Rose 2000a, Mello and Rose 2005a). Surveys were conducted in June 1996, from April to September in 1997-1999, and in April-early May and June from 2000 to 2003. In addition to the surveys, the CCGV Shamook was moored over the spawning aggregation at the Bar Haven grounds for periods of 24-36 hours in April 2002 while acoustic data were collected continuously with a calibrated EK500 split-beam echosounder with a $38 \mathrm{kHz}$ transducer deployed in a fixed position adjacent to the vessel. A video camera for species and behavioral identification and passive acoustic listening hydrophone to monitor sounds made by spawning fish were also deployed at the mooring site.

\section{Tagging}

Cod were tagged at the Bar Haven grounds with Floy T-tags in 1997 and with transmitting sonar tags in experimental releases in 1998, 2000, and 2002. In all cases, cod were caught with feather hooks on lines fished from the CCGS Shamook in depths ranging from 10 to $70 \mathrm{~m}$. In April and May 1997, 1,813 cod were tagged with Floy Ts at the Bar Haven grounds, and several thousand fish were tagged at other locations in Placentia Bay (Lawson and Rose 2000b). Recaptures were made by the commercial and scientific fisheries. The acoustic tag was the Lotek CAFT 16-3, designed to transmit a high volume $(-59 \mathrm{~dB})$ coded pulse every 5 seconds for up to 3 years. These tags were surgically implanted in adult cod (Robichaud and Rose 2001) at the Bar Haven grounds (Table 1). Tagged fish were released at the capture location on the grounds and translocated from the site in the various experiments. All telemetry surveys were made with Lotek SRX-400 receivers from small vessels (4 m Zodiak and $6 \mathrm{~m}$ RV Gecho) equipped with hydrophones.

\section{Egg potential}

During all acoustic surveys, the proportions of females, the condition of their gonads (immature, ripening, spawning, or spent), and their size were routinely assessed $(n=144,441,504,678,336,907,347$, and 365 females sampled from 1996 to 2003, respectively, ranging in length from 45 to $120 \mathrm{~cm}$ ). Fecundity was determined from females sampled in 1999 and 2003 at Bar Haven (Fudge and Rose 2008). Spawning intensity was defined as the number of ripe females on the ground during the consecutive surveys. Spawning (egg) potential was estimated through 
Table 1. Homing summary from acoustic telemetry experiments conducted with adult spawning cod at Bar Haven from 1998 to 2003. All fish were tagged with Lotek CAFT-16 long term coded pinger tags. Most mortality in these fish has resulted from fishing (30-40\% returns from the fishery), with a maximum time at liberty of over 4 years. "No." is the number of fish at liberty during the homing year from each experiment.

\begin{tabular}{lcrlccc}
\hline Experiment & $\begin{array}{c}\text { Release } \\
\text { year }\end{array}$ & No. & Relocation & $\begin{array}{c}\text { Homing } \\
\text { year }\end{array}$ & $\begin{array}{c}\text { Homing } \\
\%\end{array}$ & Reference \\
\hline 1 & 1998 & 48 & No & & na & 1 \\
1 & 1998 & 26 & No & 1999 & 39 & 1 \\
1 & 1998 & 15 & No & 2000 & 53 & 1 \\
2 & 2000 & 4 & No & 2000 & na & 2 \\
2 & 2000 & 11 & Upcurrent & 2000 & 64 & 2 \\
2 & 2000 & 8 & Downcurrent & 2000 & 25 & 2 \\
3 & 2002 & 16 & No & 2002 & na & 3 \\
3 & 2002 & 17 & On route & 2002 & 51 & 3 \\
3 & 2002 & 15 & Off route & 2002 & 13 & 3 \\
3 & 2002 & 11 & na & 2003 & 49 & 3 \\
3 & 2002 & 9 & na & 2003 & 79 & 3 \\
\hline 3 & 2002 & 9 & na & 2003 & 20 & 3 \\
\hline
\end{tabular}

${ }^{1}$ Robichaud and Rose 2001.

${ }^{2}$ Robichaud and Rose 2002.

${ }^{3}$ Windle and Rose 2005.

two calculations. First, the average acoustic backscattering coefficient for females on the grounds was calculated for each year from April to June encompassing the main spawning period in all years:

$$
S_{a}(\text { females })=\sum_{n}\left(S_{a} f\right) \mathrm{n}^{-1}
$$

where $f=$ the proportion of females from catch data, and $n$ is the number of surveys. Next, the numbers of females of each $10 \mathrm{~cm}$ length group was determined by decomposing the mean $S_{a}$ (females) by the length composition determined from the catch and the mean acoustic target strength for each length class according to $T S(\mathrm{~dB})=10 \times \log _{10}$ (length [cm]) -67.5 (Rose unpubl.). Egg potential was estimated from the total number of females of $10 \mathrm{~cm}$ length groups, the percent maturity of those groups, and their mean fecundity:

$$
\text { Egg potential }=\sum_{L 10}\left(S_{L 10} \times M \times F\right)
$$

where $S_{L 10}$ was the number of spawning females of each $10 \mathrm{~cm}$ length group, $M$ was the percent maturity of the group, and $F$ their mean fecundity. 
Finally, estimates of total spawning numbers over each year were made by integrating over 100 days (based on the detailed chronological data from 1997 to 1999 and assuming a 20 day residence for each female cod, Robichaud and Rose 2002).

\section{Egg and larval surveys}

Egg, larval, and demersal juvenile density and distribution were monitored from 1997 to 1999. Eggs and larvae were sampled over a grid of 45 stations throughout the spawning and post-spawning periods from April to August in 1997 and 1999, and from April to September in 1998, using a $4 \mathrm{~m}^{2}$ Tucker trawl and double oblique tows to $40 \mathrm{~m}$ depth. Cod eggs were staged I-IV and all stage I eggs were assumed to be cod (haddock and witch flounder with similar eggs are uncommon in Placentia Bay, Bradbury et al. 2000). Predictions of egg development time were based on mixed layer temperature (Pepin et al. 1997).

\section{Juvenile surveys}

Demersal juveniles were surveyed with a $25 \mathrm{~m}$ bottom seine once a month from September to December 1997-1999 at 18 sites around the shoreline of the bay that contained eelgrass habitat (Robichaud and Rose 2006). Numbers and standard length of cod caught were recorded. Hatch dates were calculated from an age-length relationship developed using standard lapillus daily-otolith-ring counts (D. Robichaud unpubl. data).

\section{Recruitment}

Recruitment was assessed from acoustic surveys at the Bar Haven spawning grounds at ages 4-5, and over the full management unit (NAFO 3Ps) using results from sequential population model Adapt run E, a middle estimate among several that varied (see Brattey et al. 2004). It is important to note that the sequential population analysis (SPA) was tuned primarily with two bottom trawl survey indices that do not cover the Bar Haven area. Hence the surveys do not overlap in space, but the main trawl survey was conducted at the same time in April as the acoustic survey at Bar Haven. The indices of recruitment differ in interpretation: the Bar Haven index reflects subadult and adult presence on this spawning ground (ages 4-5), whereas the stock index reflects survival of juveniles to age 3 over a greater proportion of, but not the full, stock range. Beverton-Holt stock-recruitment models were used to compare egg potential and recruitment, using a nonlinear fitting procedure assuming lognormal errors (Hilborn and Walters 1992). 


\section{Results and discussion}

\section{The Bar Haven spawning grounds}

The Bar Haven area in northwest Placentia Bay is dominated by a series of islands and underwater shoals that rise to within $50 \mathrm{~m}$ of the surface (Fig. 1). A deep channel (to $200 \mathrm{~m}$ ) penetrates the main area between Bar Haven and Woody Islands, but the main spawning area is in the shallower waters $(30-80 \mathrm{~m})$ at the margins of this channel (Windle and Rose 2006). The dominant flow in Placentia Bay is the inshore branch of the Labrador Current that hooks around the Avalon Peninsula and flows counter-clockwise around the bay. The complex bathymetry and variable winds result in many eddies and local variations to these dominant flows. Tidal elevations are variable spatially but reach peak heights of 3-4 m in the Swift Current area near the Bar Haven grounds. Temperatures are generally cool as a result of the Labrador Current waters, but surface waters warm seasonally to $10-15^{\circ} \mathrm{C}$. During the spawning season, surface waters are warming but at depths of over 40-50 m retain near zero or even subzero temperatures.

The spawning biomass at Bar Haven, as estimated from acoustic surveying, ranged from a few thousand tons in 2000 to over 25,000 t in 1998 (Fig. 2). Total stock spawning biomass estimated from sequential population models ranged from about 60,000 $\mathrm{t}$ in 1996 to about 85,000 t in 1998 and 1999 (Brattey et al. 2004). Bar Haven represented between about 2 and 30\% of the spawning biomass of the stock. The two series were weakly correlated when fit with a log model with zero intercept $(r$ $=0.48 ; p=0.07$ ) (Fig. 3).

\section{Lesson 1: Cod spawn in same area each year, but numbers and timing vary.}

Cod spawned at the Bar Haven grounds in all years from 1996 to 2003 (Figs. 2, 3). The strongest year classes on the grounds were those born in 1990, 1992, and 1997 (Fig. 4). From 1997 to 1999, and particularly in 1998, there were numbers of fish older than 7 years. From 2000 to 2003 there were very few such older fish, likely a result of a concentration of fishing effort and catch in the Bar Haven area from 1998 to 2000 (Brattey et al. 2004). From 1997 to 1999, when spawning activity was monitored near year-round, spawning was highly protracted, but peaked from April to June with a secondary peak in June or early July (Fig. 5). Early spawning coincided with export of eggs and larvae from Placentia Bay, whereas later spawning was associated with higher retention of early life stages.

The protracted spawning observed made single or short-term measures of spawning density potentially misleading in terms of spawning potential. Our measures spanned the spawning from 1997 to 1999 and the major peak from April to June in the later years (1996 was a start- 


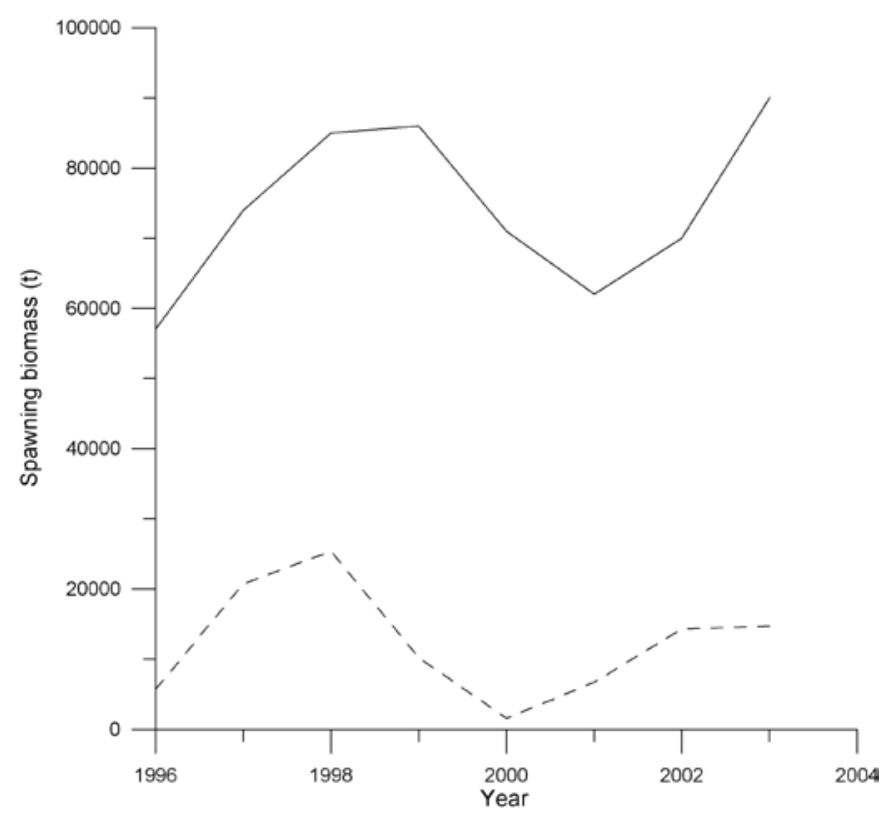

Figure 2. Spawning biomass from acoustic surveys at Bar Haven (dashed) and in the 3Ps stock.

up year with only a single measure in June). April-June measures are thought to capture the year-to-year variations (ranking the same if the full season had been used in those years, $98>97>99$ ).

The location of the spawning grounds relative to current and tidal flows results in eggs and larvae being transported seaward and out of the bay if spawning occurs early in cold waters, or more likely being retained within the bay if spawning is later under warmer conditions. Surface drifters released at the Bar Haven grounds were retained within the land-sea complex of the inner bay, many at locations similar to the distribution of eggs and juveniles (Bradbury et al. 2000, Robichaud and Rose 2006).

Lesson 2: Spawning behavior is complex, involving lekking and sound production by males and extended courtship.

In cod, courtship behavior and spawning may extend over a period of weeks or months and follows structured rituals. Males generally arrived first on the grounds (Robichaud and Rose 2002) and undertook a form of lekking behavior, in which they competed with other males in attempts to attract females (Hutchings et al. 1999, Nordeide and Folstad 


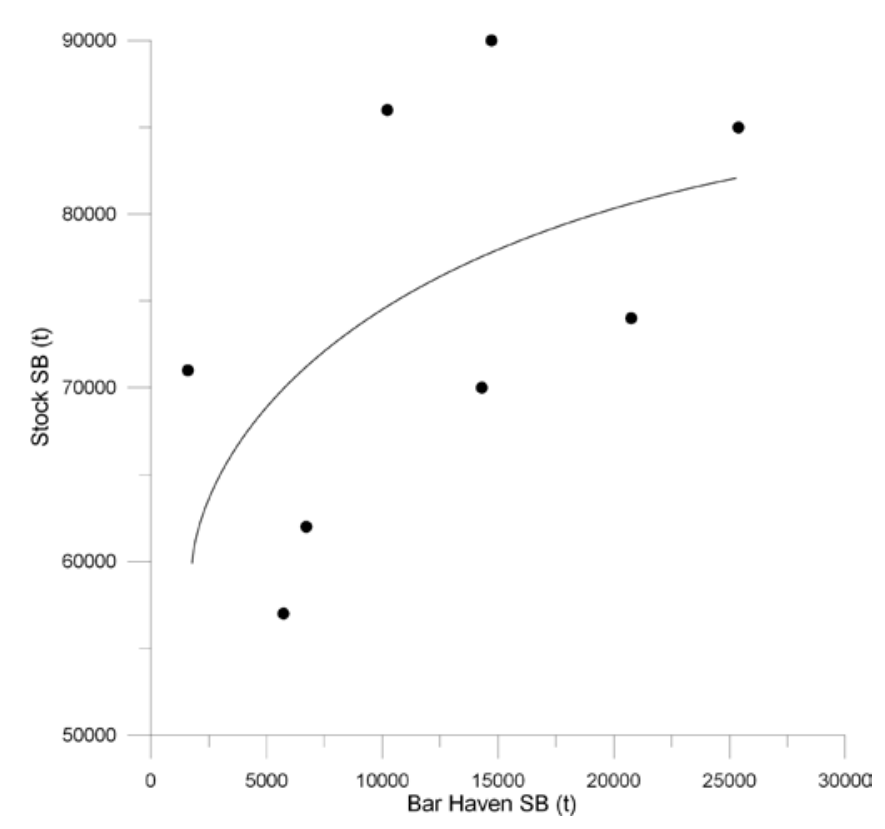

Figure 3. Spawning biomass at Bar Haven from acoustic surveys vs. the 3Ps stock spawning biomass, where $x$ and $y$ are the spawning biomass of Bar Haven and the 3Ps stock, respectively.

2000, Windle and Rose 2007). Males made grunting noises periodically by contracting muscles around their swim bladder (S.B. Fudge unpubl.). These grunts were recorded primarily at night. Females moved on and off the lekking arenas as their eggs ripened, with larger females batch spawning several times over a period of a few weeks (Robichaud and Rose 2003). Courtship and spawning involved vertical movements in the water column (the height depending on the depth of water), most notably in the evening, and can be observed as rises and falls in small groups of fish that have the appearance of columns (Rose 1993, Lawson and Rose 2000a). From a fixed station, the rises and falls of fish in a spawning group appear as a wave (Fig. 6).

\section{Lesson 3: Large fish in good condition enhance egg potential.}

There were large inter-annual differences in the spawning potential, with a major peak in 1997 and 1998 (1998 highest) (Fig. 7). This peak reflected for the most part a large total number of fish on the ground but also an older age structure (Fig. 4). For example, a large total number of fish was observed in 2003, but spawning potential was less than in 1997 and 1998 because of a younger age and smaller size structure. The 


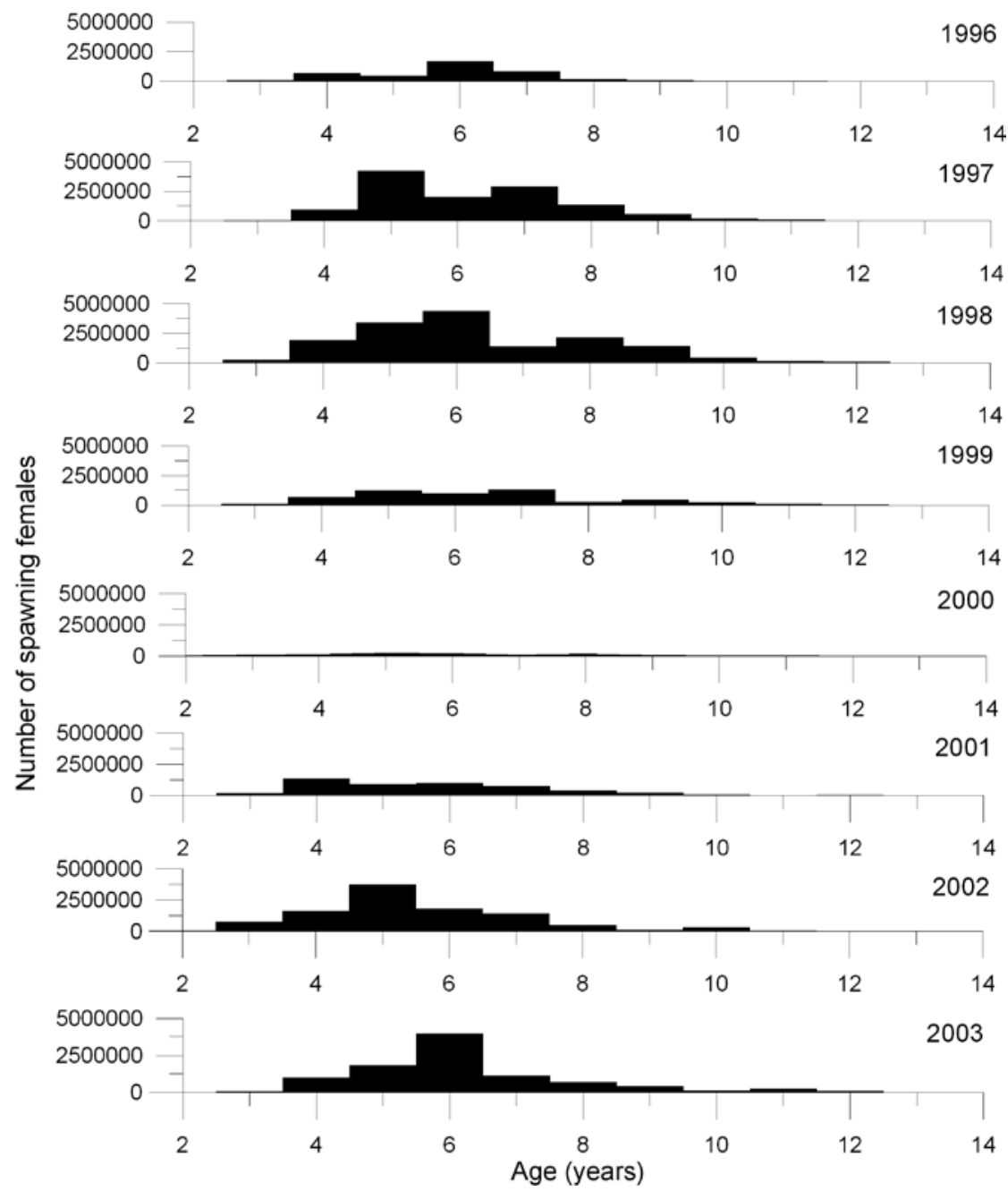

Figure 4. Age structure of cod at the Bar Haven spawning area, 1996-2003. 

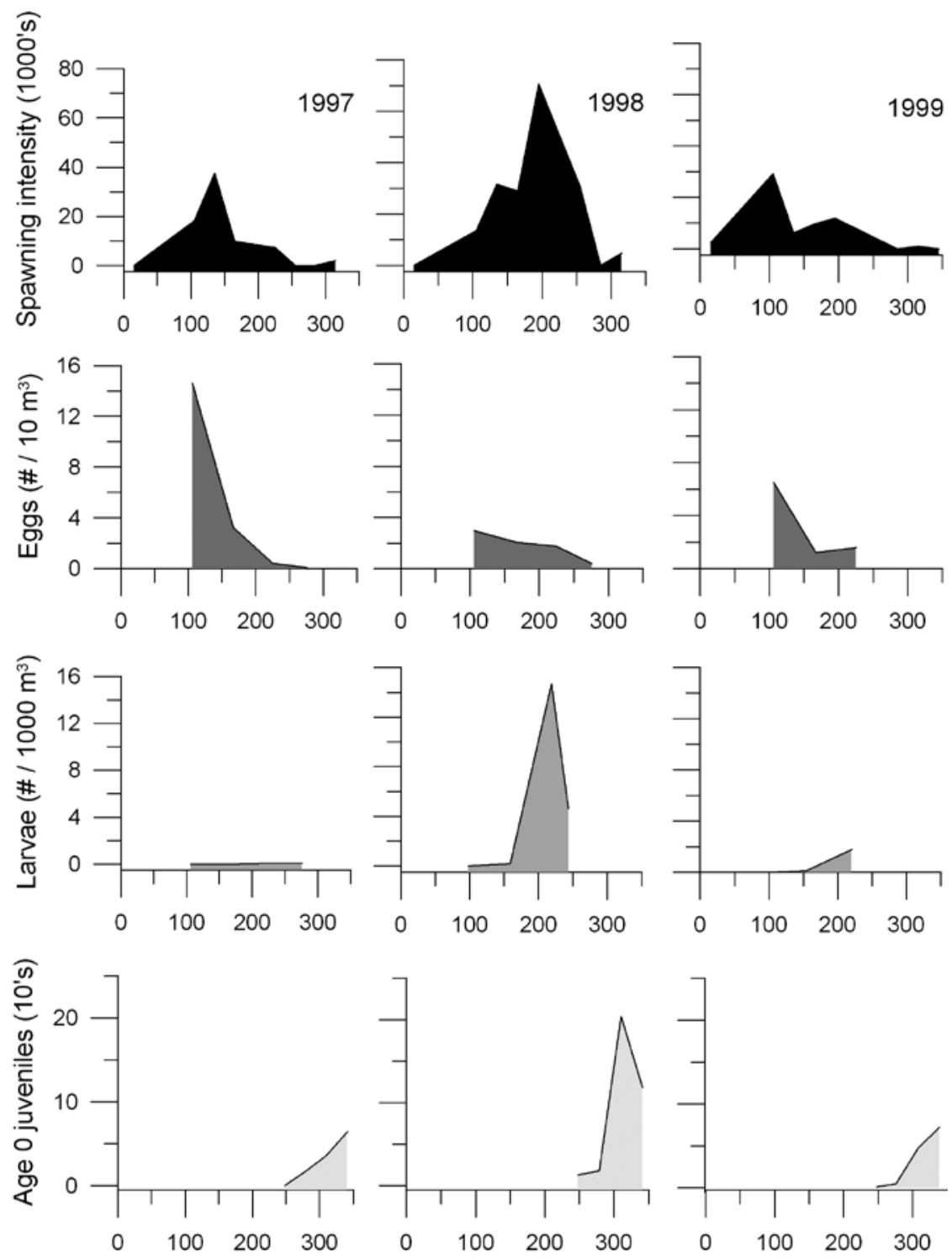

Day of year

Figure 5. Spawning intensity (ripe female numbers), egg, larval, and juvenile concentrations from 1997 to 1999 in Placentia Bay. 


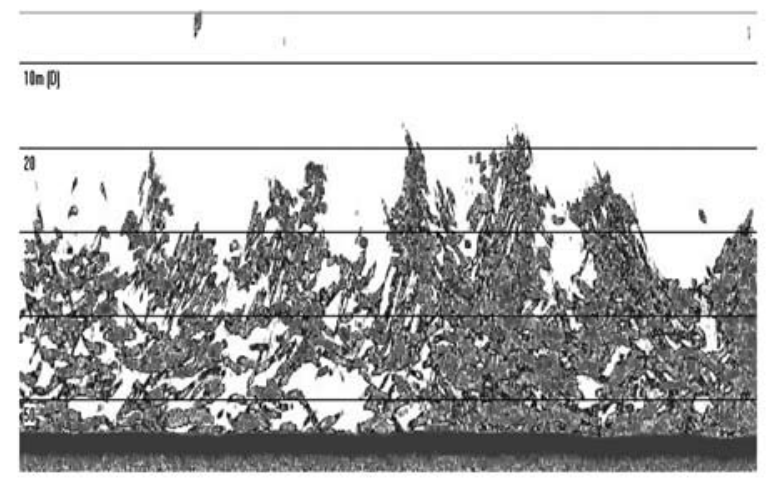

Figure 6. Echogram from stationary transducer (38 kHz) over spawning aggregation at Bar Haven in 2003. The $x$-axis represents time (approximately 15 minutes) and the $y$-axis depth (as indicated). The rises and falls of the individual fish, which form columns (Rose 1993) when observed from a moving platform, can be clearly seen.

percentage of cod aged 8 years and older reached about $14 \%$ in 1998 and 1999, but declined quickly to $9 \%$ in 2000 and $5 \%$ by 2002. Estimated annual egg production rapidly declined by 2000 , but increased somewhat in 2002 and 2003.

Liver condition in mature female cod of all size classes varied among years (ANOVA, $p<0.05$ ). Larger fish varied less in liver condition than smaller fish. Years of highest condition were 1997, 1998, and 2003. Mean annual liver condition in spawning females was correlated with annual egg potential (Fig. 8). In turn, cod with superior liver condition had isotope signatures characteristic of pelagic feeding (Sherwood et al. 2007), primarily a function of the availability of capelin in Placentia Bay (Mello and Rose 2005a). Liver condition in cod is known to be strongly related to reproductive success (Marshall et al. 2000).

Lesson 4: Retention of early life stages does not explain local recruitment.

In the three years of study of all life stages, retention did not appear to be key to resultant survival to spawning recruitment. The 1997 year class, the strongest to return to the Bar Haven grounds from 1996 to 2003, was poorly retained within the bay, with concentrations of eggs, larvae, and juveniles the lowest measured from 1997 to 1999 (Fig. 5).

Temporal trends in the progression of life stages differed substantially among years (Fig. 5). In 1997, the highest adult spawner and early 

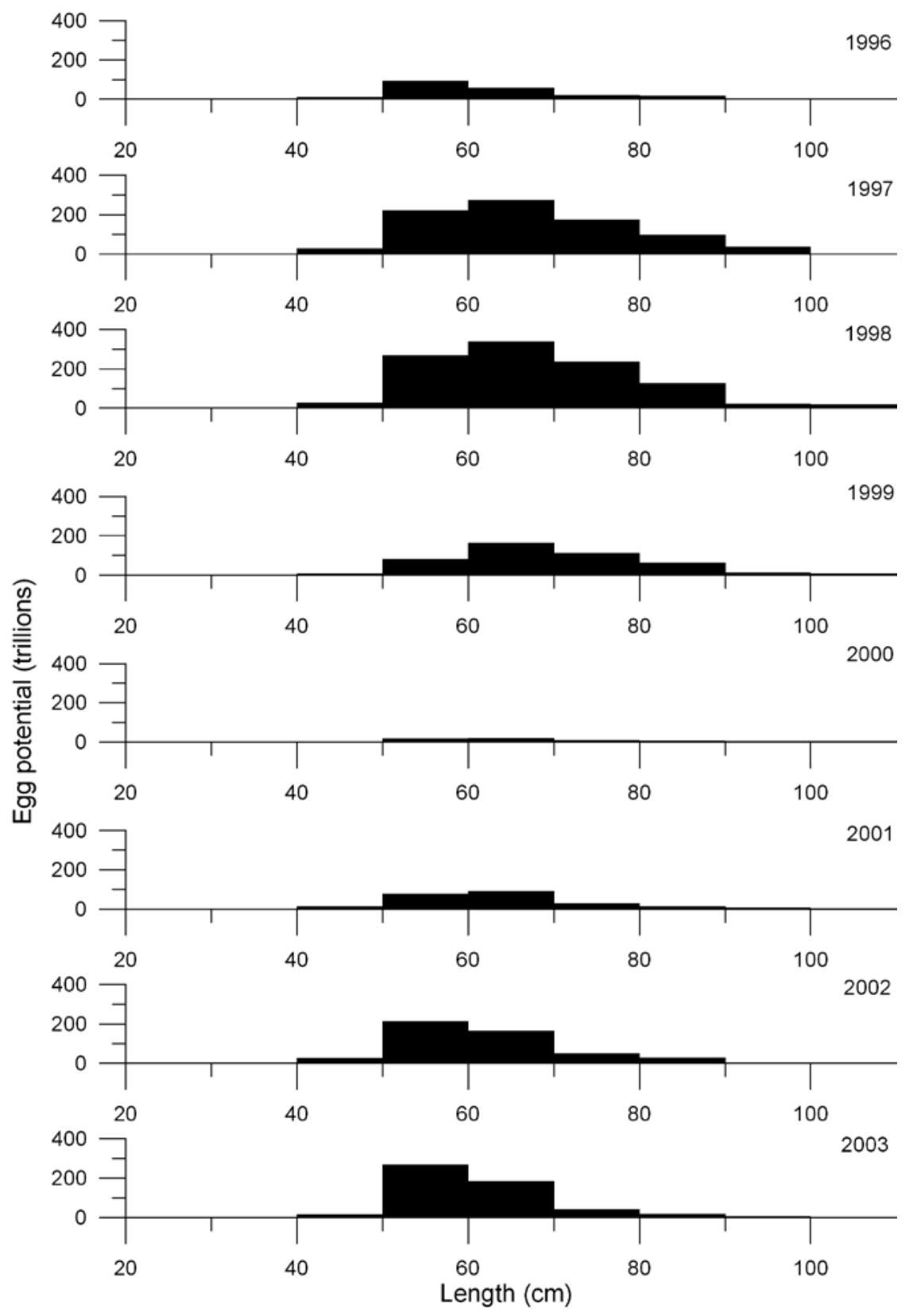

Figure 7. Annual egg production by length group at Bar Haven, 1996-2003. 


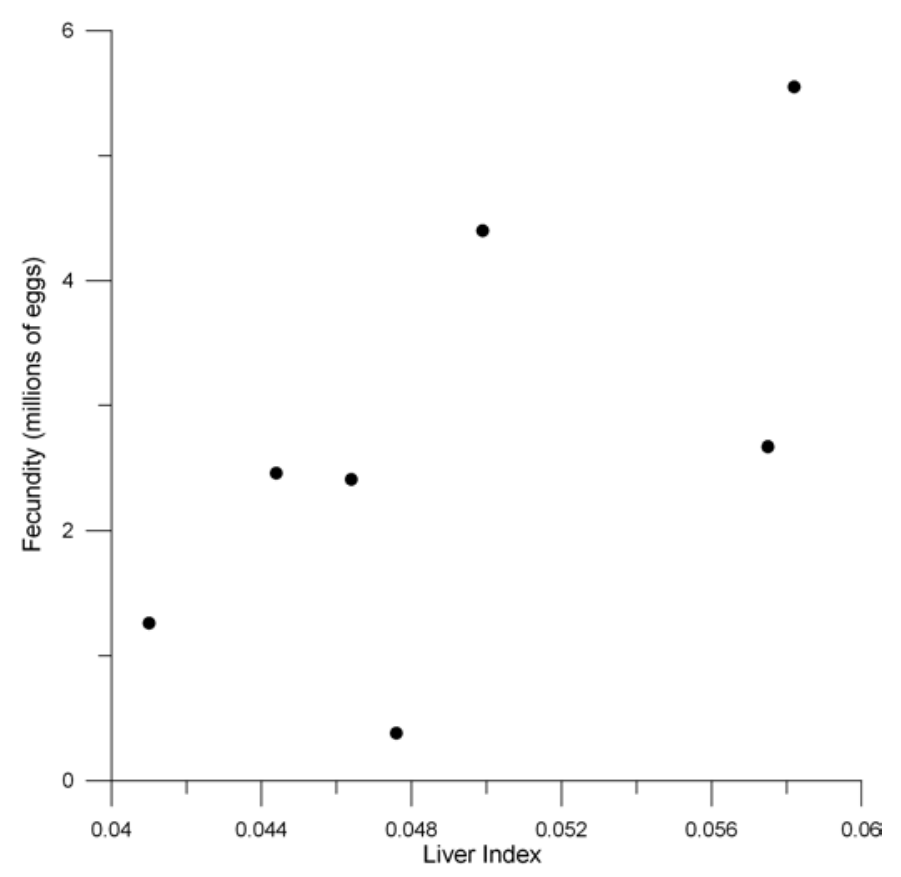

Figure 8. Annual egg potential and the mean liver index of female cod, AprilJune 1997-2003. Each datum is an annual average of the females measured (1996 is excluded because of singular sampling) ( $r=$ 0.64; $p<0.05)$. Fecundity based on Fudge and Rose 2008.

stage egg concentrations were found in April (mean surface temperature $0.0^{\circ} \mathrm{C}$ ), but only low concentrations of larvae and demersal juveniles were subsequently observed in the bay. These findings suggest that early spawning at inevitably cold temperatures led to extended development times that resulted in few larvae or juveniles being retained within the bay. In 1998, peak spawning was delayed until June when surface temperatures were $11^{\circ} \mathrm{C}$, and late stage eggs, larvae, and juveniles were more abundant within the bay (juveniles were 5 times more abundant in 1998 than in 1997). In keeping with these results, juveniles within the bay were virtually all spawned during the later peak in spawning in all years studied. Back calculations of spawning dates using otolith ages and expected egg stage durations indicated that locally retained juveniles resulted from spawning that occurred from June onward in all years. Larvae and demersal juveniles that were spawned before June were rarely observed despite an abundance of pre-June spawning in all years (Robichaud and Rose 2006). 
Annual rankings of the concentrations of the three life history stages, eggs, larvae, and juveniles, did not match with local recruitment to the Bar Haven grounds ( $97>98>>99$ ). The ranking of juvenile (and to a lesser extent larval) density matched that of full stock recruitment, as well as annual egg potential at Bar Haven (98 > $97>>99)$.

Potential annual fecundity at Bar Haven predicted the independently modeled juvenile recruitment to the larger stock area more precisely than local spawning recruitment, which also suggests that retention was not the key factor in local recruitment. We note that these conclusions are based on three years of data only (it was not feasible to extend this part of the study), and these results must be interpreted in that light. Nonetheless, these findings, in tandem with our findings on homing behavior, are consistent with recent studies indicating that homing in cod sustains population structures (Svedang et al. 2007), although at some larger scale retention is likely to be important.

\section{Lesson 5: Dispersal of both early life stages and adults is density-dependent.}

Juvenile dispersal was highly density-dependent (Robichaud and Rose 2006). When densities of juveniles were higher, they were more dispersed. This result differs substantially with past studies conducted at lower resolution on the northeast coast of Newfoundland, in which density-dependence of juveniles was not detected (Schneider et al. 1997).

Adults disperse from the Bar Haven grounds after spawning, in some years venturing around the Avalon Peninsula as far north as Trinity Bay (Lawson and Rose 2000a,b). Fish of larger size travel farther, with the exception of very large fish that become more sedentary (Lawson and Rose 2000a,b). In years of higher abundance, more fish will migrate farther. Tagging results reported in Lawson and Rose (2000b) and Brattey et al. (1999), suggest that the extent of the post-spawning migration to the north from fish tagged in Placentia Bay may have been greater in 1997 and 1998 than in the following years when the numbers of fish spawning at Bar Haven were lower.

\section{Lesson 6: Adults home in sequential years to the same spawning ground.}

Telemetry experiments conducted at the Bar Haven grounds from 1998 to 2003 showed that adult cod are capable of precise homing both in subsequent years and in the same year after being transplanted back along the spawning migration route (Table 1). The only experiments in which cod did not home at a high rate were those in which cod were displaced to what was likely to be unfamiliar territory not on the migration path (Robichaud and Rose 2002, Windle and Rose 2005; Table 1). Overall, discounting those transplant experiments, homing averaged about $60 \%$. It is important to recognize that this work does not address 


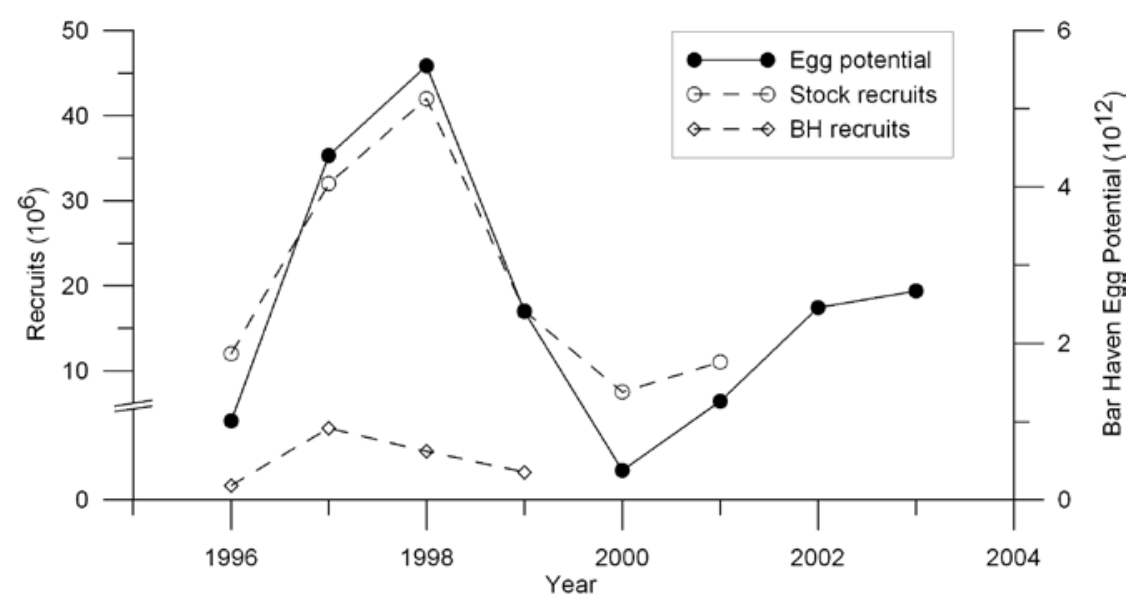

Figure 9. Egg potential at Bar Haven (closed circles), and recruits at age 3 to 3Ps stock (open circles) and to the Bar Haven grounds at age 4-5 years (open diamonds).

natal homing. The present data are not adequate to address that issue. Nevertheless, the demonstrated homing that takes place to the Bar Haven grounds is likely the mechanism that sustains this spawning group (Robichaud and Rose 2001, Windle and Rose 2005). It is equally important to note that on average $40 \%$ of cod did not home, but strayed, presumably to other spawning grounds. As many of these fish were subsequently caught in the fisheries, there is no evidence of elevated morality as a cause of non-returning fish.

Lesson 7: At low stock sizes, egg potential predicts recruitment. Overall annual spawning potential (eggs) at the Bar Haven ground from 1996 to 2000 was correlated with recruitment to the Bar Haven ground four and five years later $\left(r^{2}=0.41\right)$ and to the full fisheries management unit (NAFO subdivision 3Ps) $\left(r^{2}=0.95\right)$ in Beverton-Holt models (Figs. $9,10)$. Surprisingly, the full stock relationship was the stronger of the two, based on six years of independent data (only four years of data were available from Bar Haven). The correlation between egg potential and local recruitment may be explained by homing, but why the strong relationship exists with the full stock recruitment series is uncertain. One possibility is that Bar Haven spawning could be driving recruitment in the full stock, but it seems more likely that egg production is widely correlated. We cannot distinguish between these two notions. Nevertheless, the predictive power of the stock-recruitment relation- 


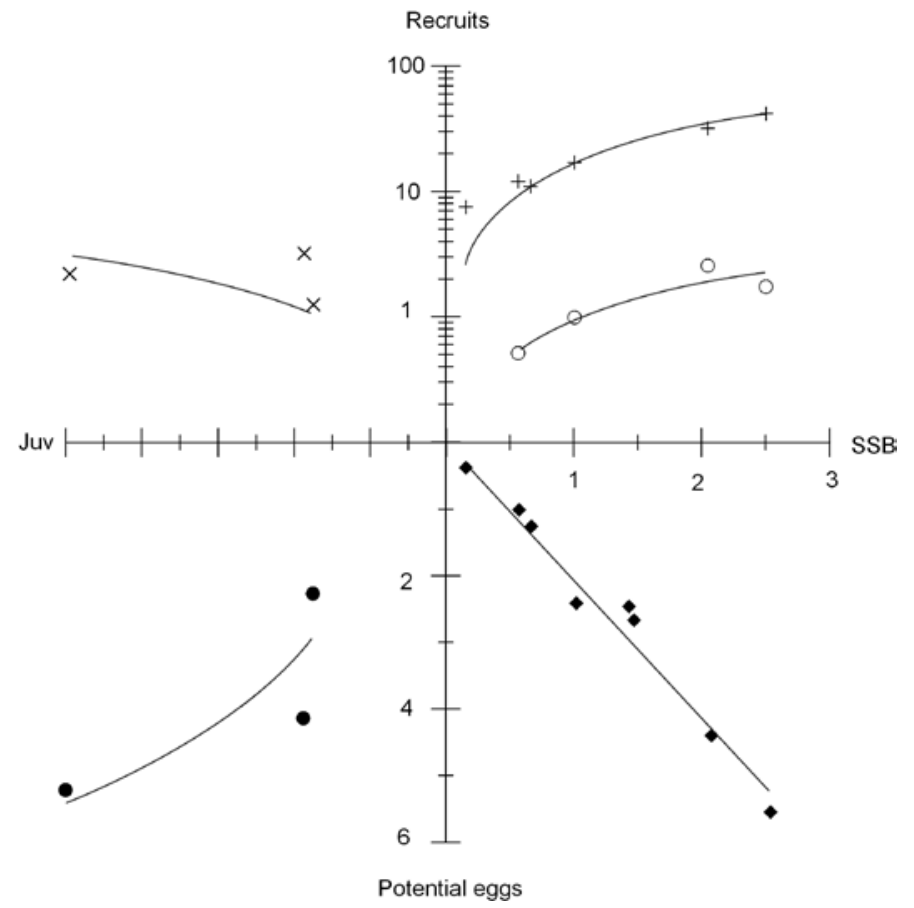

Figure 10. Paulik or life history diagram (Nash and Dickey-Collas 2005) of cod showing relationships between spawning stock biomass (SSB), egg potential, juvenile density, and recruits both to the Bar Haven grounds and to the full 3Ps stock. SSB in $10^{4} \mathrm{t}$; Potential eggs $\times 10^{12}$; Juveniles indexed; and recruits $\times 10^{6}$. Juveniles have no units (index only).

ship offers the possibility that recruitment might be predicted several years in advance by a relatively simple monitoring of one key spawning ground. It is also important to note that although potential fecundity appears to be a much more reliable index of actual stock size for stockrecruitment analyses than is biomass or numbers (Marshall et al. 1998), and this was true in our study, most of the variability in egg production was explained by the more easily measured spawning stock biomass.

A lower slope of the stock (egg production)-recruitment relationship at Bar Haven relative to the full stock suggests that at lower stock sizes there will be a greater tendency for local recruitment, and that at larger stock sizes more dispersion of recruits to a greater area will take place. This relationship has important implications for rebuilding of Atlantic cod stocks, and perhaps those of other species, where some sub-stock 


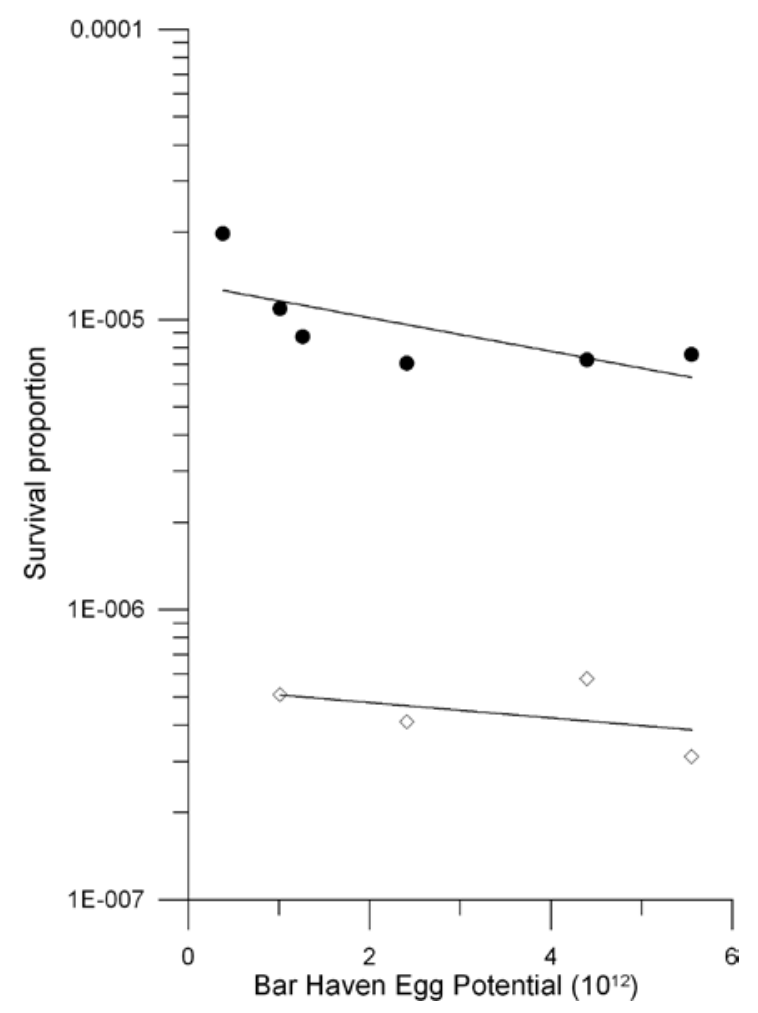

Figure 11. Survivorship from egg potential spawned at Bar Haven to subsequent spawning recruits back to Bar Haven (open diamonds) and to the full stock (closed circles).

components have fared better than others, and where expansion of the more productive components may be key to rebuilding.

It is important to note that there was little evidence in our data of strong compensation in survival rates from egg to adult (Fig. 11). Nor was there evidence of strong depensation, which has been postulated for the more depressed stocks of northern and Grand Bank cod (e.g., Frank and Brickman 2000, Anderson and Rose 2001, Rose 2004). At Bar Haven, recruitment was more or less directly related to egg potential, with similar rates of survival evident at all but the lowest production. The relationship with the full stock is also shown in Fig. 11, although we make no claims of cause and effect. 


\section{Lesson 8: Differential fishing mortality may harm spawning components.}

The NAFO division 3Ps cod stock includes several spawning grounds that may comprise reproductive populations (Lawson and Rose 2000a,b; Bradbury et al. 2000). The fishery opened in 1997 tended to concentrate effort in Placentia Bay, and in particular in the Bar Haven area. From 1998 to 2000 the fishing intensity was extreme during the spring and late fall, when cod tend to aggregate at Bar Haven. As much as 35-40\% of the total catch from 3Ps came from Placentia Bay during these years (FRCC 2002), and as much as 33\% from the resident population (Mello and Rose 2005a). A steep decline in the numbers of fish spawning at Bar Haven is evident after 1998, preceding the decline in the full stock (Fig. 2). In addition, the rate of increase in spawning biomass in the full stock suggested by the population model has been much more modest at the Bar Haven grounds. The year-to-year decline in returns of spawning cohorts of ages 5-10 years averaged 0.85 from 1997 to 2003 (equivalent to instantaneous mortality $Z$ with the assumption of sequential homing or similar proportion of the stock returning to Bar Haven each year). This assumption was almost certainly violated in year 2000 when fish did not return to the grounds. (The reasons are not known but large concentrations of fish were located in the deep channel of the bay in spawning condition, but they did not come to the Bar Haven grounds that year.) Hence, the data show a systematic decline in all age classes in 2000 and an untenable increase in 2001, but in all other years the assumption of homing is reasonable. In contrast, estimates of fishing mortality from the SPA population model, pooled over the same ages, ranged from less than 0.2 to about 0.4 during the same period (add 0.2 for $M$ ) (Brattey et al. 2004). These data suggest that the mortality rate of the Bar Haven spawning fish was considerably higher than in the general population, and a decline in egg production and then recruitment were immediate and delayed results, respectively. Additional tagging experiments conducted at Bar Haven support this conclusion (see Brattey et al. 2004).

\section{Lesson 9: Seasonal fisheries may influence fishing mortality and commercial yield and value.}

Cod exhibited strong seasonality in weight and condition, reaching highest levels in late fall and lowest in spring during spawning (Mello and Rose 2005b). Simulations based on data collected during this research indicated that fishing during spawning required mortality to be $8-17 \%$ higher to catch the same quota by weight as a fall fishery. Moreover, spring and summer fisheries resulted in lower yield (6\%) and quality (5-26\%) of fish products (Mello and Rose 2005b). 


\section{Conclusions}

Detailed study of a part of the range of a fish stock, in particular key spawning grounds, with subsequent linkages through the life history and the next generation of recruits, can yield insights into the population dynamics of a fish stock that might be lost with the broader but less detailed measures typical of most stock assessments (e.g., Brattey et al. 2004). We believe that our observations are of particular importance to cod and other stocks that are at low population levels, where former sub-stock structures have either been reduced or even eradicated by overfishing or failing production. We draw the following conclusions with reference to the ecology and management of rebuilding cod (and other) stocks:

1. Monitoring of the abundance and age structure of spawning groups and their egg potential offers a simple and effective means of tracking the present state and future potential of a fish stock;

2. Fishing on spawning grounds without restricting catch quotas to that local group risks differential reduction and overfishing of critical spawning components in fish stocks having multiple spawning grounds (such as the one studied here);

3. Fishing on spawning grounds risks differential removal of the largest spawners and hence reducing disproportionately egg potential and recruitment. Spawning behavior is complex hence intrusive fishing could reduce reproductive success;

4. During the spawning season, cod are in their poorest somatic condition, and commercial quality and yield will be poorer than during the fall period;

5. A reasonable number of large cod in a spawning population (ca. 15\%), here 8 years and older, will enhance potential fecundity, and provide an indication that fishing mortality is not too high. Large numbers of younger, smaller spawners are less likely to produce strong recruitment; and

6. Compensatory rates of survival of early life stages may not occur at low stock sizes. The formerly dominant offshore spawning groups of cod in Newfoundland waters were reduced to perhaps $1-2 \%$ of their historic levels in the last half of the twentieth century, and are very likely to be in a depensatory state (Rose 2004). The Placentia Bay cod, although reduced, at their lowest point were likely not less than $10-20 \%$ of historical levels, and appear to exhibit neither strong compensation nor depensation. 
Finally, evaluation of alternative management strategies and tests of the population effects of the biological hypotheses advanced here could be based on simulations (e.g., Kell et al. 2007). For example, the close relationship between egg potential and stock recruitment from 1996 to 2000 predicts that recruitment will decline in the early 2000s in the NAFO 3Ps cod stock, with some recovery in the 2002-2003 year classes (this prediction will be tested in the coming years). Our results also highlight the importance of conserving local cod spawning groups (Wroblewski et al. 2005), indeed allowing their abundances to increase (Shelton et al. 2006), as a step toward rebuilding the formerly larger components of stocks.

\section{Acknowledgments}

We thank crews of the RV Mares, RV Innovation, CCGS Shamook, and CCGS Teleost, S. Fraser, B. Oake, D. Methven, and numerous students for contributions to this work. We also thank two anonymous reviewers for several insightful comments on an earlier paper, including the suggestion of using a Paulik diagram to show some of our results. This research was funded by the NSERC Industrial Chair in Fisheries Conservation at the Marine Institute, Memorial University.

\section{References}

Allen, R. 2000. The new Penguin English dictionary. Penguin, London. 1642 pp.

Anderson, J.T., and G.A. Rose. 2001. Offshore spawning and year-class strength of northern cod (2J3KL) during the fishing moratorium, 1994-1996. Can. J. Fish. Aquat. Sci. 58:1386-1394.

Bradbury, I.R., P.V.R. Snelgrove, and S. Fraser. 2000. Transport and development of eggs and larvae of Atlantic cod, Gadus morhua, in relation to spawning time and location in coastal Newfoundland. Can. J. Fish. Aquat. Sci. 57:1761-1772.

Brattey, J., G.L. Lawson, and G.A. Rose. 1999. Seasonal migration patterns of Atlantic cod (Gadus morhua) in subdivision 3Ps based on tagging experiments during 1997-1998. Canadian Stock Assessment Secretariat Research Document No. 99/37.

Brattey, J., N. Cadigan, B.P. Healey, G.R. Lilly, E.F. Murphy, P.A. Shelton, and J.-C. Mahé. 2004. Assessment of the cod (Gadus morhua) stock in NAFO subdivision 3Ps in October 2004. Canadian Science Advisory Secretariat No. 2004/083.

Cook, R.M. 1998. A sustainability criterion for the exploitation of the North Sea cod. ICES J. Mar. Sci. 55:1061-1070.

deYoung, B., and G.A. Rose. 1993. On recruitment and distribution of Atlantic cod (Gadus morhua) off Newfoundland. Can. J. Fish. Aquat. Sci. 50:2729-2741. 
Frank, K.T., and D. Brickman. 2000. Allee effects and compensatory population dynamics within a stock complex. Can. J. Fish. Aquat. Sci. 57:513-517.

FRCC. 2002. Report on NAFO subdivision 3Ps cod. Fisheries Resources Conservation Council, Ottawa.

Fudge, S.B., and G.A. Rose. 2008. Changes in fecundity in a stressed population: Northern cod (Gadus morhua) off Newfoundland. In: G.H. Kruse, K. Drinkwater, J.N. Ianelli, J.S. Link, D.L. Stram, V. Wespestad, and D. Woodby (eds.). Resiliency of gadid stocks to fishing and climate change. Alaska Sea Grant, University of Alaska Fairbanks.

Hilborn, R., and C.J. Walters. 1992. Quantitative fisheries stock assessment. Chapman and Hall, New York. 570 pp.

Hutchings, J.A. 1999. Influence of growth and survival cost of reproduction on Atlantic cod (Gadus morhua). Can. J. Fish. Aquat. Sci. 56:1612-1623.

Hutchings, J.A., T.D. Bishop, and C.R. McGregor-Shaw. 1999. Spawning behaviour of Atlantic cod, Gadus morhua: Evidence of mate competition and mate choice in a broadcast spawner. Can. J. Fish. Aquat. Sci. 56:97-104.

Kell, L.T., I. Mosqeira, P. Grosjean, J.-M. Fromentin, D. Garcia, R. Hillary, E. Jardim, S. Mardle, M. Pastoors, J.J. Poos, F. Scott, and R.D. Scott. 2007. FLR: An open-source framework for the evaluation and development of management strategies. ICES J. Mar. Sci. 64:640-646.

Lawson, G.L., and G.A. Rose. 2000a. Small-scale spatial and temporal patterns in spawning of Atlantic cod (Gadus morhua) in coastal Newfoundland waters. Can. J. Fish. Aquat. Sci. 57:1011-1024.

Lawson, G.L., and G.A. Rose. 2000b. Seasonal distribution and movements of coastal cod (Gadus morhua L.) in Placentia Bay, Newfoundland. Fish. Res. 49:61-75.

Liermann, M., and R. Hilborn. 2001. Depensation: Evidence, models and implications. Fish Fish. 2:33-58.

Marshall, C.T., N.A. Yaragina, B. Adlandsvik, and V. Dolgov. 2000. Reconstructing the stock-recruitment relationship for northeast arctic cod using a bioenergetic index of reproduction. Can. J. Fish. Aquat. Sci. 57:2433-2442.

Marshall, C.T., O.S. Kjesbu, N.A. Yaragina, P. Solemdal, and O. Ulltang. 1998. Is spawner biomass a sensitive measure of the reproductive and recruitment potential of northeast arctic cod? Can. J. Fish. Aquat. Sci. 55:1766-1783.

Mello, L.G.S., and G.A. Rose. 2005a. Seasonal variation in abundance and stock composition of Atlantic cod (Gadus morhua L.) in Placentia Bay, Newfoundland, in relation to fisheries. Fish. Res. 74:142-156.

Mello, LG.S., and G.A Rose. 2005b. Seasonal cycles in weight and condition in Atlantic cod (Gadus morhua L.) in relation to fisheries. ICES J. Mar. Sci. 62:1006-1015.

Myers, R.A., K.G. Bowen, and N.J. Barrowman. 1999. Maximum reproductive rate of fish at low population sizes. Can. J. Fish. Aquat. Sci. 56:2404-2419.

Myers, R.A., N.J. Barrowman, J.A. Hutchings, and A.A. Rosenberg. 1995. Population dynamics of exploited fish stocks at low population levels. Science 269:1106-1108. 
Nash, R.D.M., and M. Dickey-Collas. 2005. The influence of life history dynamics and environment on the determination of year class strength in North Sea herring (Clupea harengus L.). Fish. Oceanogr. 14:279-291.

Nordeide, J.T., and I. Folstad. 2000. Is cod lekking or a promiscuous group spawner? Fish Fish. 1:90-93.

Pepin, P., D.C. Orr, and J.T. Anderson. 1997. Time to hatch and larval size in relation to temperature and egg size in Atlantic cod. Can. J. Fish. Aquat. Sci. 54(Suppl. 1):2-10.

Robichaud, D., and G.A. Rose. 2001. Multiyear homing of Atlantic cod to a spawning ground. Can. J. Fish. Aquat. Sci. 58:2325-2329.

Robichaud, D., and G.A. Rose. 2002. The return of cod transplanted from a spawning ground in southern Newfoundland. ICES J. Mar. Sci. 1285-1295.

Robichaud, D., and G.A. Rose. 2003. Sex differences in cod residency on a spawning ground. Fish. Res. 60:33-43.

Robichaud, D., and G.A. Rose. 2006. Density-dependent distribution of demersal juvenile Atlantic cod (Gadus morhua) in Placentia Bay, Newfoundland. ICES J. Mar. Sci. 63:766-774.

Rose, G.A. 1993. Cod spawning on a migration highway in the north-west Atlantic. Nature 366:458-461.

Rose, G.A. 2004. Reconciling overfishing and climate change with stock dynamics of Atlantic cod (Gadus morhua) over 500 years. Can. J. Fish. Aquat. Sci. 61:1553-1557.

Roughgarden, J., and F. Smith. 1996. Why fisheries collapse and what to do about it. Proc. Natl. Acad. Sci. 93:5078-5083.

Schneider, D.C., D.A. Methven, and E.J. Dalley. 1997. Geographic contraction in juvenile fish: A test with northern cod (Gadus morhua) at low abundances. Can. J. Fish. Aquat. Sci. 54(Suppl. 1):187-199.

Shelton, P.A., A.F. Sinclair, G.A. Chouinard, and R. Mohn. 2006. Fishing under low productivity conditions is further delaying recovery of Northwest Atlantic cod (Gadus morhua). Can. J. Fish. Aquat. Sci. 63:235-238.

Sherwood, G.D., R.M. Rideout, S.B. Fudge, and G.A. Rose. 2007. Influence of diet on growth, condition and reproductive capacity in Newfoundland and Labrador cod (Gadus morhua): Insights from stable carbon isotopes $\left(\delta^{13} \mathrm{C}\right)$. Deep-Sea Res. II 54:2794-2809.

Svedang, H., D. Righton, and P. Jonsson. 2007. Migratory behaviour of Atlantic cod Gadus morhua: Natal homing is the prime stock-separating mechanism. Mar. Ecol. Prog. Ser. 345:1-12.

Walters, C.J., and S.J.D. Martell. 2004. Fisheries ecology and management. Princeton University Press. 399 pp.

Windle, M.J.S., and G.A. Rose. 2005. Migration route familiarity and homing of transplanted Atlantic cod (Gadus morhua). Fish. Res. 75:193-199.

Windle, M.J.S., and G.A. Rose. 2007. Do cod form spawning leks? Evidence from a Newfoundland spawning ground. Mar. Biol. 150:671-680.

Wroblewski, J.S., B. Neis, and K. Gosse. 2005. Inshore stocks of Atlantic cod are important for rebuilding the East Coast fishery. Coastal Management 33:411-432. 
